\title{
The First Example of the Solid State Thermal Cyclometalation of Ligated Benzophenone Imine Giving Novel Luminescent Platinum(II) Species
}

\author{
Yulia Yu. Scaffidi-Domianello, ${ }^{\dagger,}$ Alexey A. Nazarov, ${ }^{\dagger}$ Matti Haukka, ${ }^{\S}$ Markus Galanski, ${ }^{*}{ }^{\dagger}$ \\ Bernhard K. Keppler, ${ }^{\dagger}$ Jacob Schneider, ${ }^{\diamond}$ Pingwu Du, ${ }^{\diamond}$ Richard Eisenberg,,${ }^{, \diamond}$ \\ and Vadim Yu. Kukushkin**
}

\section{Synopsis}

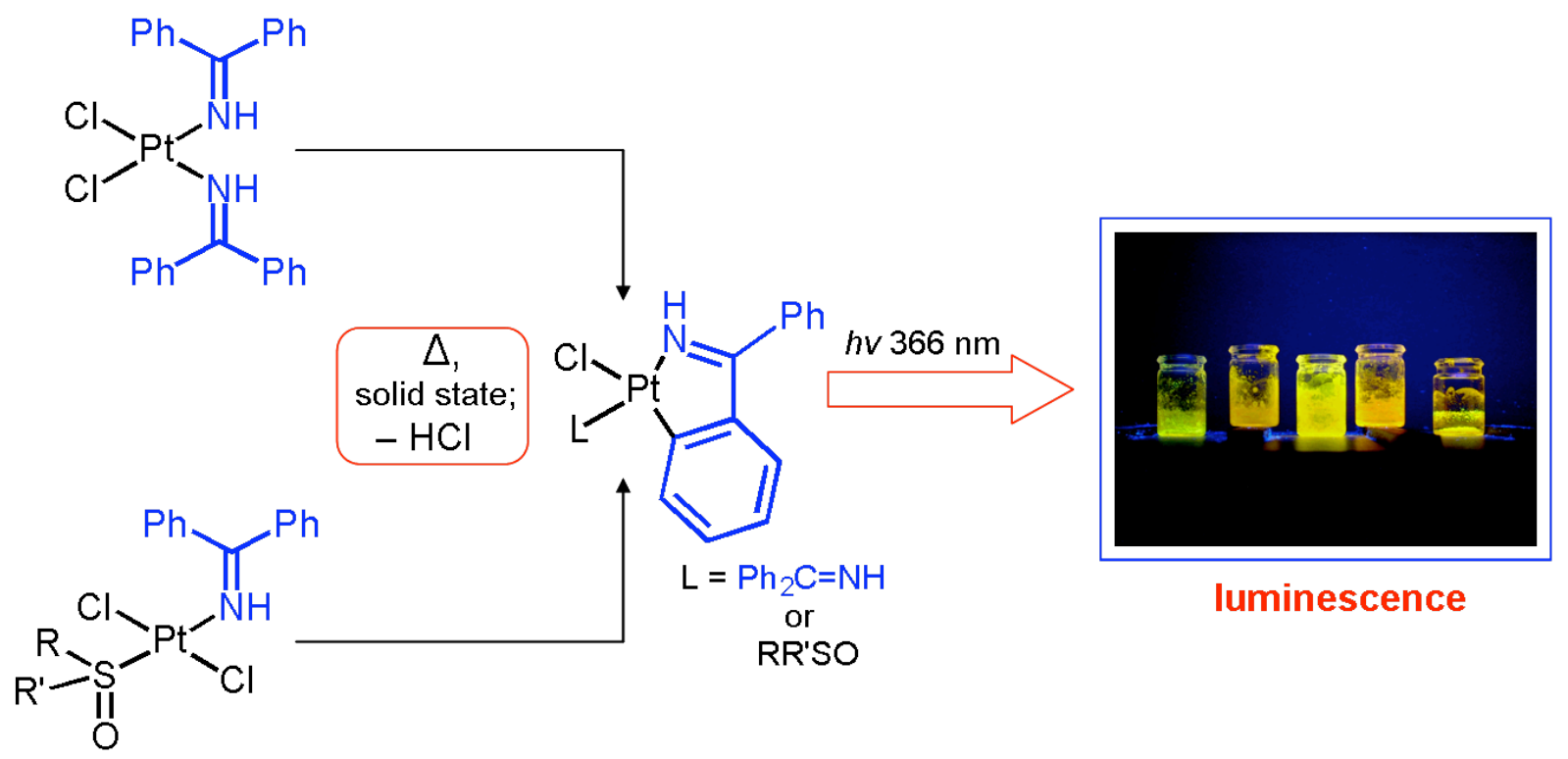

$\mathrm{Pt}^{\mathrm{II}}$-complexed benzophenone imine undergoes cyclometalation upon heating either in the solid state or in toluene suspension to give novel luminescent species. 